\title{
Nano-Scale Fission Product Phases in an Irradiated U-7Mo Alloy Nuclear Fuel
}

\author{
D. D. Keiser, Jr., ${ }^{\star}$ Brandon Miller, James Madden, Jan-Fong Jue, and Jian Gan
}

Idaho National Laboratory, 2525 Fremont Ave., Idaho Falls, ID 83402

*dennis.keiser@inl.gov

\section{Introduction}

Irradiated nuclear fuel is a very difficult material to characterize. Due to the large radiation fields associated with these materials, they are hard to handle and typically have to be contained in large hot cells. Even the equipment used for performing characterization is housed in hot cells or shielded glove boxes. The result is not only a limitation in the techniques that can be employed for characterization, but also a limitation in the size of features that can be resolved. The most standard characterization techniques include light optical metallography (LOM), scanning electron microscopy (SEM), and electron probe microanalysis (EPMA). These techniques are applied to samples that are typically prepared using grinding and polishing approaches that will always generate some mechanical damage on the sample surface. As a result, when performing SEM analysis, for example, the analysis is limited by the quality of the sample surface that can be prepared. However, a new approach for characterizing irradiated nuclear fuel has recently been developed at the Idaho National Laboratory (INL) in Idaho Falls, Idaho. It allows for a dramatic improvement in the quality of characterization that can be performed when using an instrument like an SEM. This new approach uses a dual-beam scanning microscope, where one of the beams is a focused ion beam (FIB), which can be used to generate specimens of irradiated fuel $(\sim 10 \mu \mathrm{m} \times 10 \mu \mathrm{m})$ for microstructural characterization, and the other beam is the electron beam of an SEM. One significant benefit of this approach is that the specimen surface being characterized has received much less damage (and smearing) than is caused by the more traditional approaches, which enables the imaging of nanometersized microstructural features in the SEM. The process details [1] are for an irradiated low-enriched uranium (LEU) U-Mo alloy fuel. Another type of irradiated fuel that has been characterized using this technique is a mixed oxide fuel [2].

With respect to irradiated U-Mo alloy fuel, the characterization of FIB cross-section samples using SEM has revealed first-of-a-kind images of phases present in the microstructure. These phases discussed in this paper are solid phases that result from the nuclear fission process. These phases are comprised of constituents called "fission products." Overall, fission product elements can be gases, liquids, or solids during reactor operation, and an SEM can be employed to evaluate the solid phases. The development of these phases is important because they can influence a very important parameter of nuclear fuel called "swelling." Swelling is the increase in volume of the fuel as the U-235 is fissioned in a reactor. If too much dimensional change occurs, the cooling channels of a fuel assembly can be closed, and the fuel could overheat, breach, or even melt. The size and location of solid fission product phases in the fuel microstructure can impact the ultimate performance of the fuel in a reactor. In irradiated oxide fuel, a significant solid fission product phase is the 5-metal phase that contains $\mathrm{Pd}, \mathrm{Rh}, \mathrm{Ru}$, Tc, and Mo, which typically forms on grain boundaries [3]. In irradiated LEU U-Mo fuel, solid fission product phases that contain $\mathrm{Sr}, \mathrm{Ba}, \mathrm{Nd}, \mathrm{Y}$, and $\mathrm{Te}$ have been observed in the fission gas bubbles of irradiated fuel TEM samples produced using a traditional sample preparation approach [4]. In order to gain information from larger, more representative regions of a fuel sample, it is advantageous to use SEM. However, for samples produced using more conventional approaches, there is a limit as to how effectively these solid precipitate phases can be resolved, regardless of whether TEM or SEM is used, in part because of the limitation in sample preparation.

This paper will demonstrate how one can take advantage of the negligible sample surface damage during the FIB process, especially compared to the more traditional mechanical polishing process that uses grinding papers, polishing cloths, slurries, and diamond pastes. Focus will be given to nano-scale, solid fission product phases that have been resolved in heavily irradiated LEU U-7Mo dispersion fuel. With these never-before-reported images of fission product phases, one can develop a much better understanding of how these solid fission product phases may impact the swelling behavior of the fuel after different irradiation times in a nuclear reactor.

\section{Materials and Methods}

The U-Mo alloy interrogated in this work contained $7 \mathrm{wt} . \%$ Mo and was irradiated in INL's Advanced Test Reactor (ATR) as part of the Global Threat Reduction Initiative Program's High Performance Research Reactor Fuel Development Program. This is a program that is developing low-enriched uranium $(\mathrm{U}-235<20 \%)$ fuels for application in research and test reactors [5]. The sample to be characterized came from a location of a fuel plate $(2.5 \mathrm{~cm}$ wide by $10 \mathrm{~cm}$ long) that had been irradiated to a local fission density of around $5.2 \times 10^{21}$ fissions $/ \mathrm{cm}^{3}$, where this number represents the amount of U-235 that was fissioned. After irradiation and proper cooling at the ATR, the fuel plate was transferred to the Hot Fuel Examination Facility so that a small sample could be "punched" from the fuel plate. This punching process involved using a press located in the hot cell to generate a small cylinder, around $1.4 \mathrm{~mm}$ tall and $1.0 \mathrm{~mm}$ in diameter, from the irradiated dispersion fuel plate [6]. This type of fuel plate is comprised of dispersion fuel meat encased in Al-6061 cladding. The fuel meat contains U-7Mo fuel particles in an Al alloy matrix. During fabrication and irradiation, an interaction zone can develop between the fuel particles the $\mathrm{Al}$ alloy matrix, and this zone can go amorphous during irradiation [7].

Once the punched sample was produced, it was transferred to the Electron Microscopy Laboratory, where it was mounted and polished through $1 \mu \mathrm{m}$ diamond paste in a glove box. 


\section{A Leap in Sensitivity
and Speed with the \\ A Leap in Sensitivity
and Speed with the XR401 sCMOS \\ Camera}

- Cryo TEM

- Low Dose TEM

- Diffraction

- In-Situ TEM

- Extraordinary speed

- Non-Blooming Sensor - $<2$ e/pixel noise

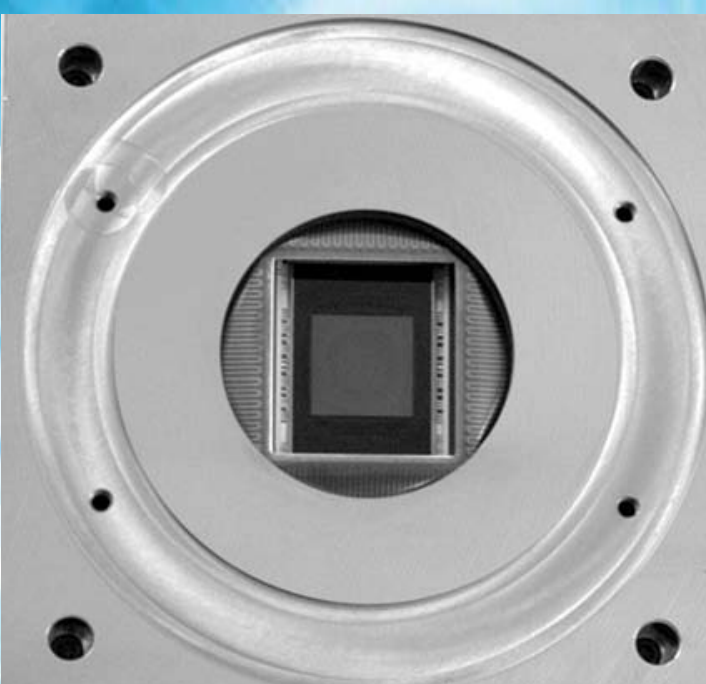

Adenovirus

Dr. Cameron Ackerley

The Hospital for Sick Children

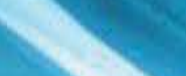

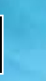

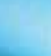


The sample was transferred into a FEI Quanta 3D dual beam FIB. All cross sections were produced in the instrument using standard FIB techniques. The process has been found to be very material- and process-dependent (this means that beam current conditions will change with changes in the process or the material). The following method was employed to produce cross sections with viewable dimensions of $\sim 15 \mu \mathrm{m} \times 10 \mu \mathrm{m}$. The first step was to deposit a Pt protective layer on the sample surface to reduce curtaining and minimize damage to the specimen surface during milling operations ( $\mathrm{Pt}$ was deposited using $30 \mathrm{kV}$ $100 \mathrm{pA}$ ion beam conditions with a rectangular box pattern). Once the protective layer has been placed, coarse milling operations were initiated. For coarse milling operations, the following ion beam conditions were used: a $30 \mathrm{kV}, 7 \mathrm{nA}$ ion beam, regular cross section box, and multiscan scan pattern. Approximately $1 \mu \mathrm{m}$ of specimen material was left in front of the Pt protective layer; this material was milled away during "clean up" for SEM analytical examination. To clean up the beam damage (amorphous layer) from the coarse mill, the ion beam conditions were set to $30 \mathrm{kV}, 1 \mathrm{nA}$, using a cleaning cross section box pattern, with dimensions $20 \mu \mathrm{m} \mathrm{X}, 700 \mathrm{~nm} Y, 10 \mu \mathrm{m} Z$. Once complete, the ion beam current was stepped down to $500 \mathrm{pA}, 300 \mathrm{pA}$, and $100 \mathrm{pA}$, respectively, repeating the cleaning cross section pattern (for this set, the pattern $Y$ axis was reduced to $200 \mathrm{~nm}, 75 \mathrm{~nm}$, and $50 \mathrm{~nm}$, respectively). At this point in time, the ion beam has reduced the amorphous layer and has worked its way up and into the Pt protective layer along $Y$ axis. Furthermore, the face of the specimen cross-sectional area right in front of the Pt deposit has a prepared (ion-polished) surface for SEM examination with minimum FIB-induced artifacts. SEM imaging of microstructural features can be performed using secondary electrons.

\section{Results}

Figure 1a shows a secondary electron image (SEI) of the surface of a polished irradiated fuel sample after FIB cross-section samples were produced for more detailed characterization. Figure $1 b$ shows an example of an SEM image that was produced from the mechanically polished top surface shown in Figure 1a. This image will be compared to those generated from FIBed cross-section samples discussed later. A large fraction of the microstructure in Figure $1 \mathrm{~b}$ is comprised of pores (dark features), and in some of the pores, solid fission product phases are located. The pores form during irradiation of the nuclear fuel as a result of the constant generation of fission gases (primarily $\mathrm{Xe}$ and $\mathrm{Kr}$ ) that have negligible solubility in the fuel matrix. At the stage of irradiation for this sample, it was surmised that the solid fission products have migrated to the fission gas bubbles and have precipitated and grown in size.

Figure 2 shows a SEI of the microstructure revealed at a FIB cross section of the sample. Fission gas bubbles tens of nanometers in size can be observed. Outside the FIB cross section is the mechanically polished sample surface. It can be seen that more of the microstructure is revealed where the FIB sample was produced. Higher magnification images (up to $35,000 \times$ ) of the microstructure revealed in the FIB cross section are presented in Figure 3. Careful evaluation of these images shows that a region near a fuel-matrix interaction layer has large, round bubbles, as opposed to areas further into the U-7Mo fuel (a)

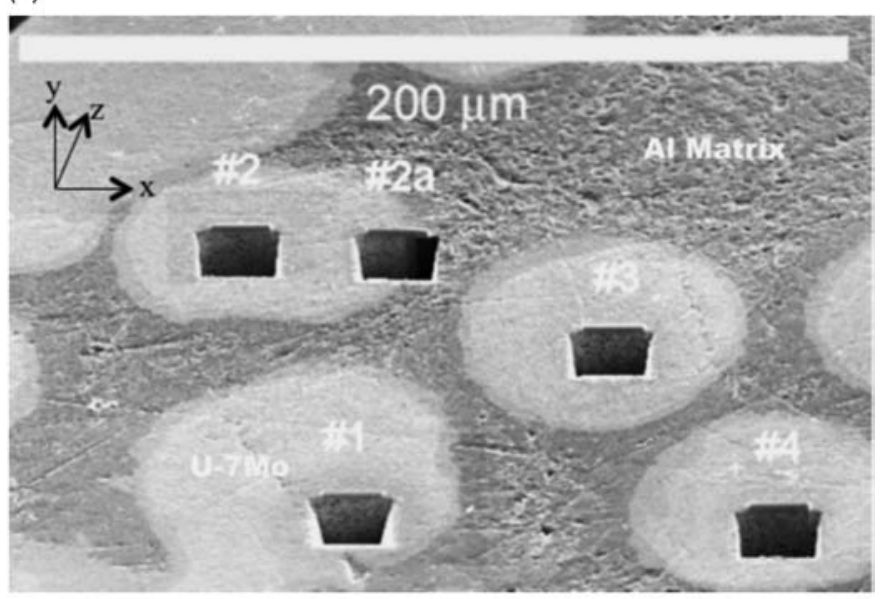

(b)

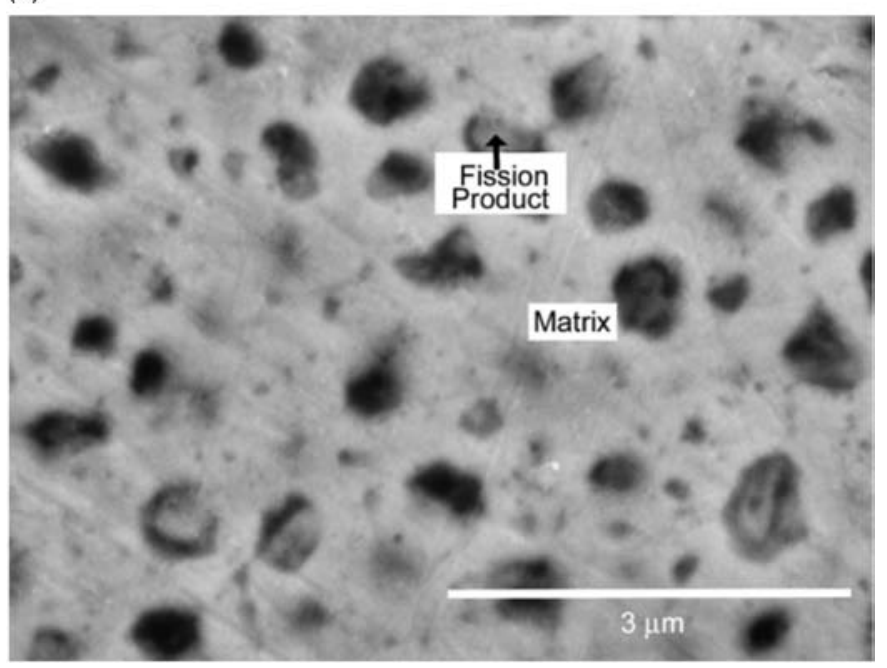

Figure 1: SEls showing (a) five locations where cross-section samples were produced using FIB from the polished surface of an irradiated U-7Mo dispersion fuel plate, and (b) the microstructure of the U-7Mo matrix (labeled "Matrix"), pores (black), and solid fission product phases (medium contrast) that can be resolved from the polished surface.

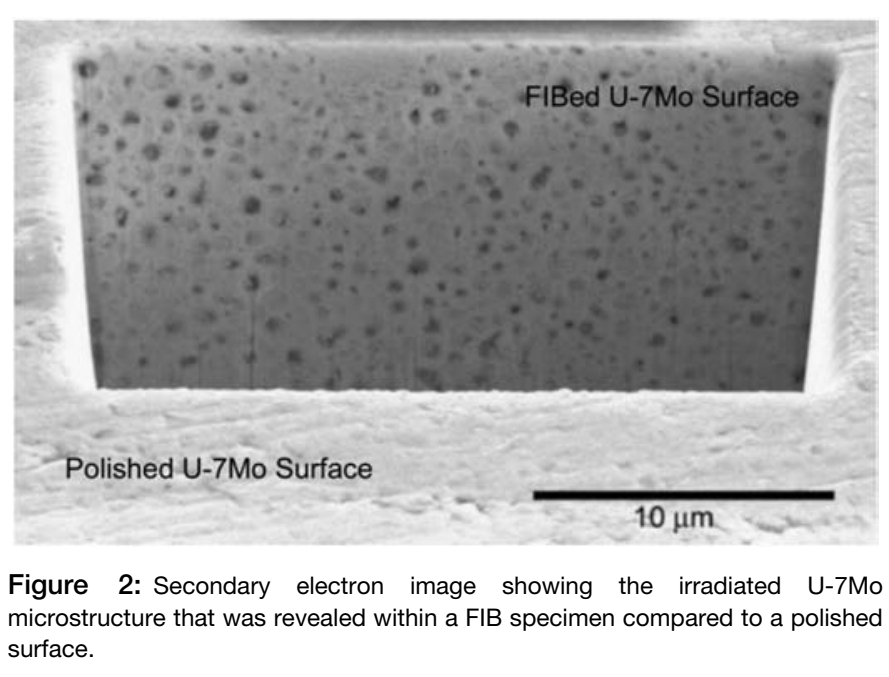

where the bubbles are smaller and more faceted. The white line drawn in Figure 3a delineates these two regions. It has been shown that the microstructural regions on either side of the 
(a)

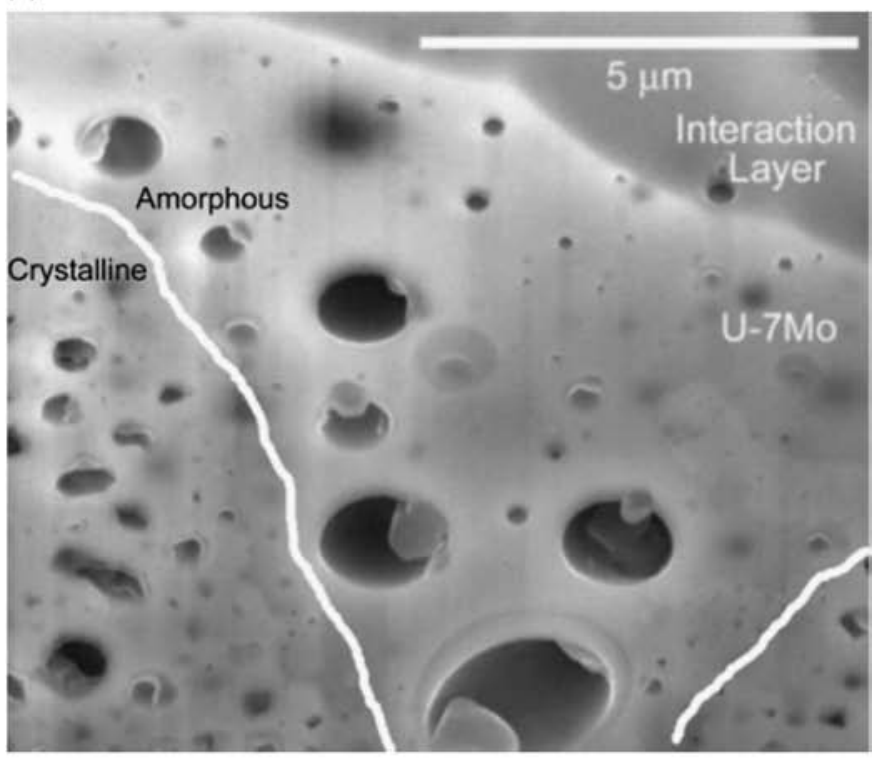

(b)

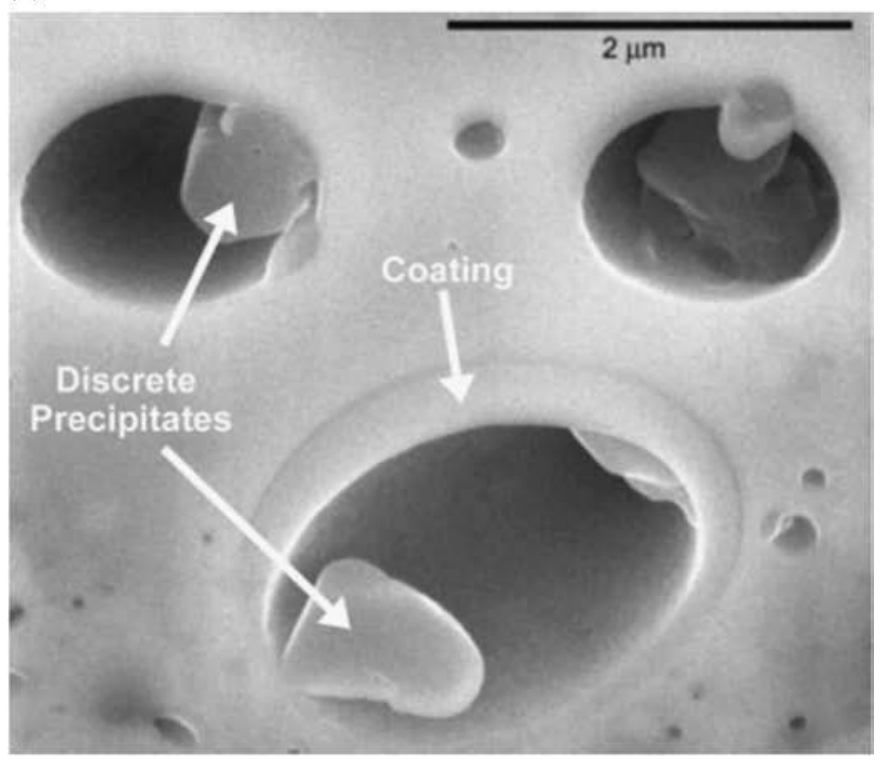

Figure 3: Secondary electron image of the irradiated U-7Mo microstructure at the FIB sample location. (a) Low magnification and (b) higher magnification.

white line differ in terms of the crystallinity of the material. The side nearest the interaction layer has been observed to contain $\mathrm{Si}$, which has diffused into the U-7Mo from the interaction layer during irradiation, and has gone amorphous, while on the other side of the line, the U-7Mo has remained crystalline [4]. In the amorphous material, the bubbles are larger and round compared to the smaller, more faceted bubbles (this may reflect a difference in the surface energy of the two microstructures). Overall, the crystalline nature of the U-7Mo seems to dramatically affect the size and shape of the fission gas bubbles. For the solid fission product phases, an amorphous layer is observed to coat the inner surface of some bubbles (see Figure 3b) in either crystalline or amorphous regions. In addition, discrete precipitates are observed. Focusing on the shape of the discrete precipitates, Figure 4 shows plate-shaped, round, and faceted precipitates. Figure 5 shows the plate-shaped precipitates at (a)

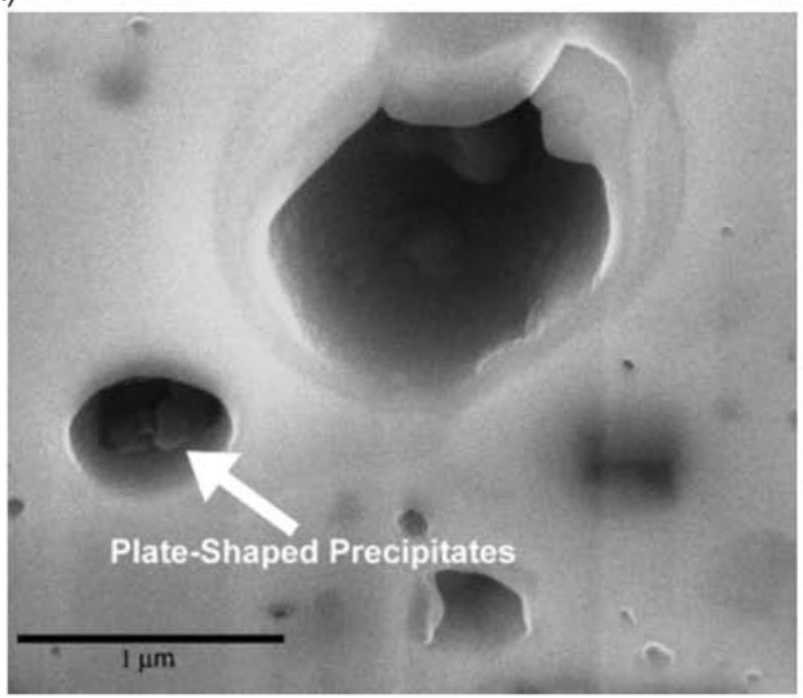

(b)

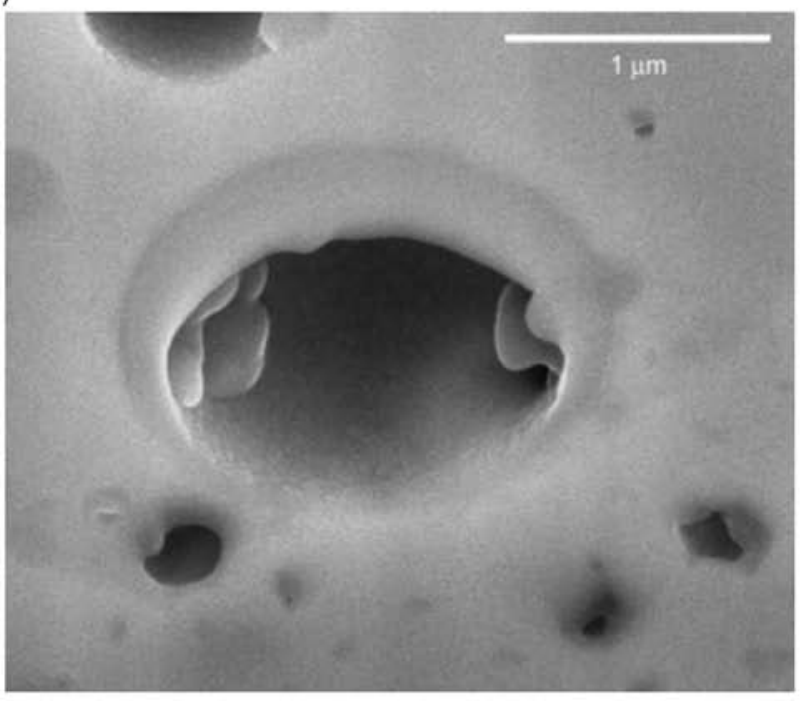

(c)

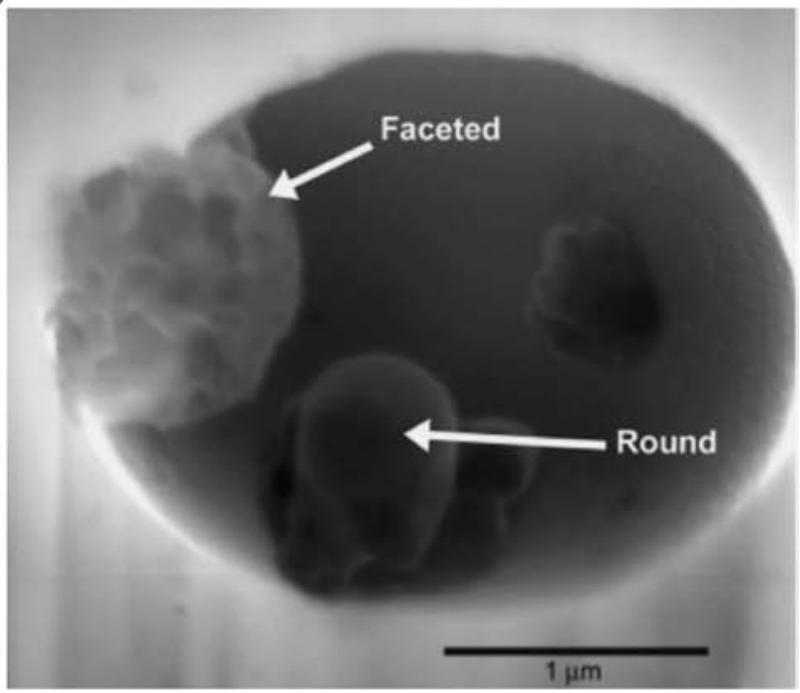

Figure 4: Secondary electron images of solid fission product phases with different shapes: plate-shaped preciptates $(a, b)$ and faceted and round precipitates (c). 
(a)

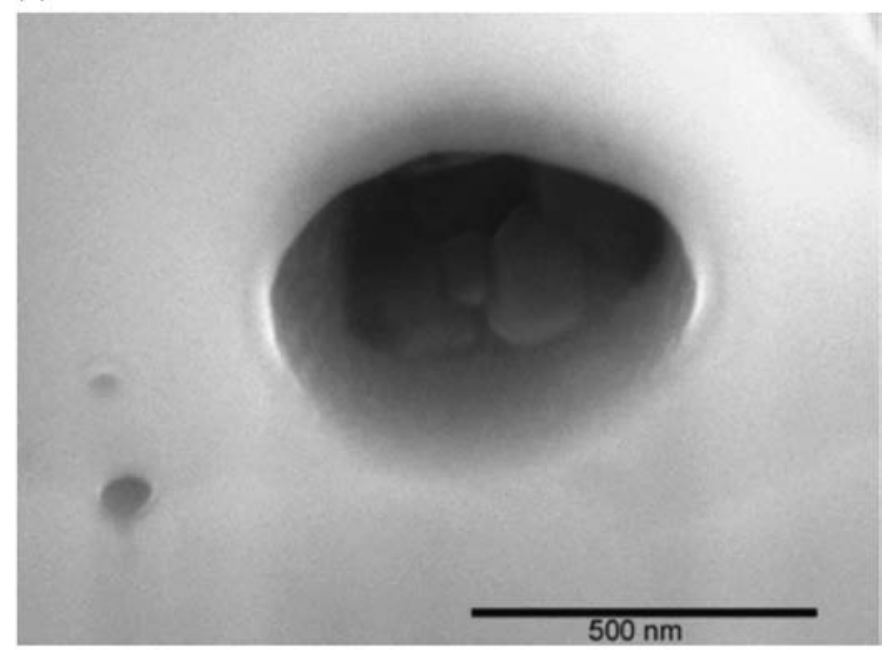

(b)

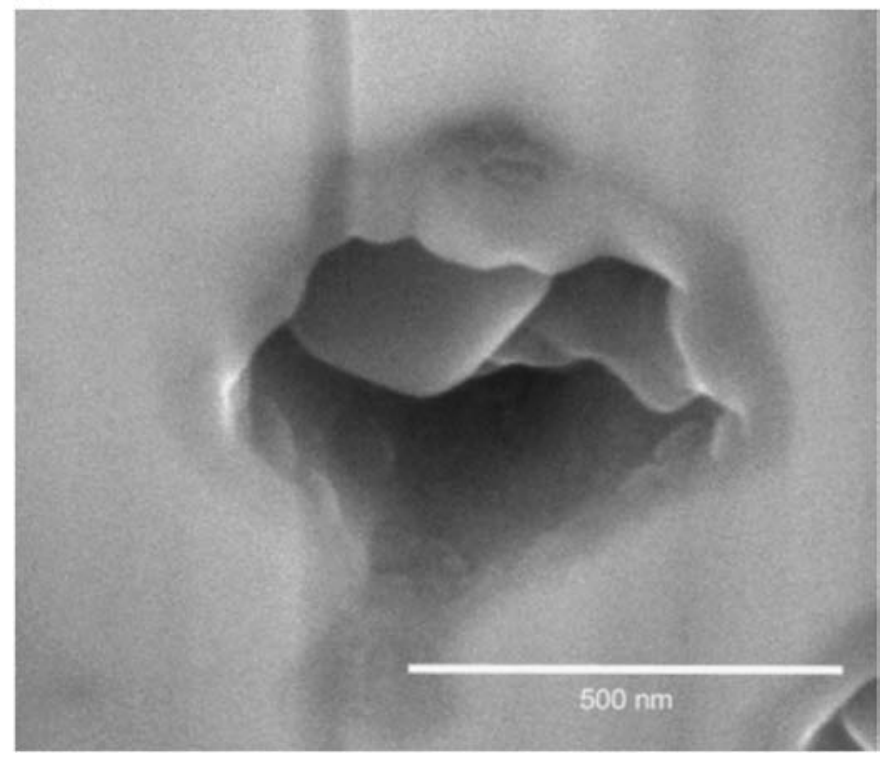

Figure 5: Two examples of high-magnification secondary electron images of the platelet-shaped precipitates present in fission gas bubbles.

a magnification that is high enough to reveal features tens of nanometers in size. The mechanisms that potentially cause some solid fission products to form layers and others discrete precipitates are not currently understood. One significance of the observation that solid fission product phases precipitate and grow on the inside of fission gas bubbles is that this reduces the space available within the bubbles for the fission gases to reside. It is speculated that as the fission gas bubble space becomes reduced, a driving force may be generated for the fission gases to migrate to different regions of the fuel plate microstructure such as the fuel-cladding interaction region.

\section{Discussion}

Images of solid fission product phases present in the fission gas bubbles of irradiated U-7Mo nuclear fuel, like the ones shown in this paper for FIB cross-section samples, as best as the authors can determine, have not been reported in the open literature. The data that can be extracted from these images provide important information about the size, shape, and distribution of fission gas bubbles and solid fission product phases per unit volume of irradiated nuclear fuel at a particular fission density, which is important for improving understanding of the swelling behavior of the fuel.

\section{Conclusion}

Based on careful evaluation of the images presented in this article, the following conclusions can be drawn: (1) solid fission product phases can appear as a layer that coats the inside surface of fission gas bubbles; (2) discrete precipitate phases can nucleate and grow with a wide range of shapes (plates, spheres, faceted, etc.) on the inner surface of fission gas bubbles; (3) the bubbles nearest a fuel/matrix interaction layer are relatively large and round compared to ones observed further into the irradiated U-7Mo alloy, which appear more faceted; and (4) the fission gas bubbles present in the microstructure range from a few nanometers to a few microns in size and exhibit a fairly random distribution.

\section{Acknowledgments}

This manuscript has been authored by Battelle Energy Alliance, LLC, under Contract No. DE-AC07-05ID14517 with the U.S. Department of Energy. The U.S. Government retains and the publisher, by accepting the article for publication, acknowledges that the U.S. Government retains a nonexclusive, paid-up, irrevocable, world-wide license to publish or reproduce the published form of this manuscript, or allow others to do so, for U.S. Government purposes. We thank the HFEF staff, located at INL, for its contributions in generating punchings used for conducting the SEM analysis. Acknowledgment is given to the ATR staff for their assistance in performing the irradiation experiments.

\section{U. S. Department of Energy Disclaimer}

This information was prepared as an account of work sponsored by an agency of the U.S. Government. Neither the U.S. Government nor any agency thereof, nor any of their employees, makes any warranty, express or implied, or assumes any legal liability or responsibility for the accuracy, completeness, or usefulness of any information, apparatus, product, or process disclosed, or represents that its use would not infringe privately owned rights. References herein to any specific commercial product, process, or service by trade name, trademark, manufacturer, or otherwise, does not necessarily constitute or imply its endorsement, recommendation, or favoring by the U.S. Government or any agency thereof. The views and opinions of authors expressed herein do not necessarily state or reflect those of the U.S. Government or any agency thereof.

\section{References}

[1] BD Miller et al., J Nucl Mater 424 (2012) 38-42.

[2] M Teague et al., J Nucl Mater 444 (2014) 475-80.

[3] Hj Matzke and H Blank, J Nucl Mater 166 (1989) 120-31.

[4] J Gan et al., J Nucl Mater 424 (2012) 43-50.

[5] DD Keiser et al., JOM-J Min Met Mat S 55(9) (2003) 55-58.

[6] DE Janney, AB Robinson, TP O'Holleran, RP Lind, M

Babcock, LC Brower, J Jacobs, and PK Hoggan. Hot

Laboratories and Remote Handling Plenary Meeting,

Bucharest, Romania, Sept. 20-21, 2007.

[7] J Gan et al., J Nucl Mater 396 (2010) 234-39. 


\section{Innovation at SPI Supplies}

\section{UV Prep"} FOR SEM

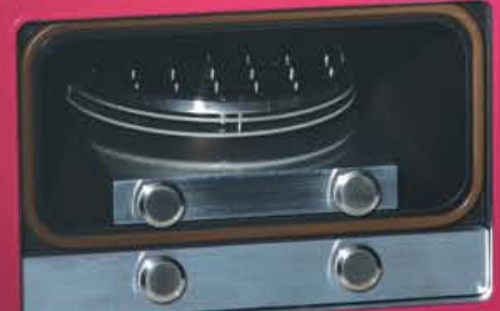

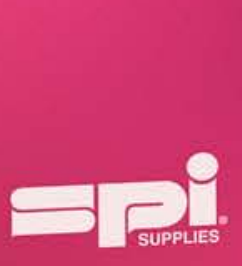

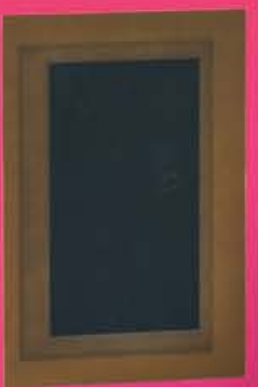

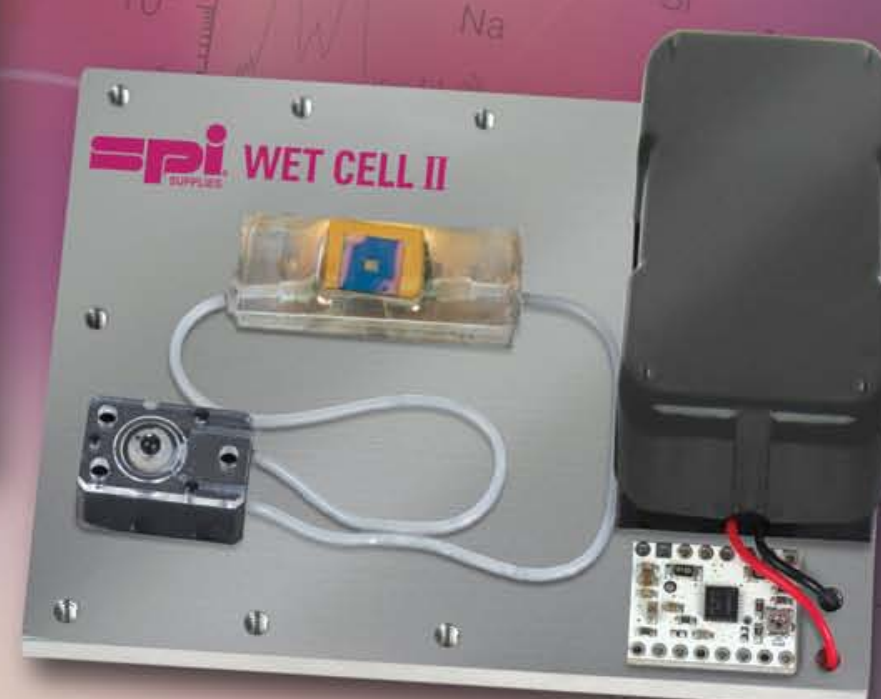

\section{UV Prep for SEM • Wet Cell II}

\section{Get more detail from your SEM samples.}

The UV Prep uses a customized UV source to effectively attack and break up hydrocarbon bonds. At the same time, reactive species of oxygen react with these hydrocarbon bonds forming molecules such as $\mathrm{H} 2 \mathrm{O}, \mathrm{CO}$ and $\mathrm{CO} 2$, which are pumped out of the chamber. The result is a surface free of hydrocarbon contamination.

\section{Liquid Probe System for SEM/EDS, EPMA and TOF-SIMS systems.}

The Wet Cell II is the next generation device for the examination of liquids in an EM environment. The self contained high vacuum compatible device enables the analyst to characterize a fluid in its natural state.

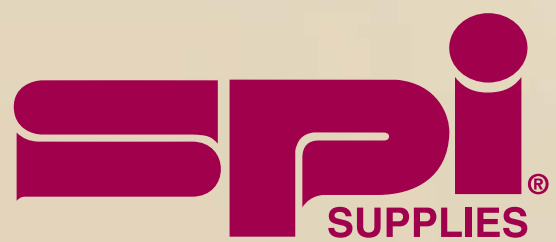

SPI Supplies Division of STRUCTURE PROBE, Inc. 